\title{
TRUST AND HABIT AS KEY SUCCESS ON DIGITAL CONSUMING BEHAVIOR IN INDONESIA MEDIATED BY BEHAVIOR INTENTION
}

\author{
Daduk Mansur ${ }^{1 *}$, Ernie Sule ${ }^{2}$, Dwi Kartini ${ }^{3}$, and Yevis Marty Oesman ${ }^{4}$ \\ 1,2,3,4 Universitas Padjadjaran, Indonesia
}

\begin{abstract}
Personal perception as a fundamental factor on consumer buying behaviour especially on online shopping, triggered by internet access all over the world. In Indonesia personality aspect becomes a key factor regarding new technology adoption. Big internet user not yet automatically increased the use of e-commerce. Indonesia has big potential market for e-commerce. Unfortunately, the e-commerce user in Indonesia is still $12 \%$ from total internet user in Indonesia. It is very important to find factors i.e. Trust (T) and Habit (H), which affects the use behaviour of e-commerce. This study aims to find out the perfect model that fits the use behaviour of e-commerce in Indonesia. In this study,we conduct literature review and primary data survey. Statistical result is analysed using war Partial Least Square (PLS) with 547 respondents from 4 e-commerce providers user. We found that $T$ (Trust) and $H$ (Habit) have positive influence on Behaviour Intention (BI), BI positive influence on Use Behaviour (UB) e-commerce. Based on the results, we build a fit model and validate the data regarding e-commerce user behaviour. The fit model is expected to guide provider to find the key success factor in e-commerce business in Indonesia and are expected to become an innovation and important factors as an academic contribution. Based on these results we recommend operator to build good perception regarding Habit $(H)$ and Trust $(T)$.
\end{abstract}

Keywords: Habit; Trust, Behavior Intention, Use Behavior

\section{INTRODUCTION}

Indonesia has potential market for e-commerce business with a huge potential revenue. Indonesia takes rank 2 (two) in internet users in Asia and ranked sixth from all over the world (123 million) (eMarketer, 2015). Unfortunately, the potential revenue is still loss because the number of e-commerce user only takes about $12 \%$ from the total internet user (AT Kearney, 2015). This shows a strong indication that acceptance and use of e-commerce are still problems. Effect from this condition makes a potential in lost revenue for business e-commerce in Indonesia up to US\$ 30 Billion (A.T. Kearney, 2015).

E-commerce data shows recording significant from year-on-year growth of 6070 per cent since 2014, the Indonesian e-commerce market is still relatively small (US\$8 billion) compared to regional pace-setter, China, sales of US\$692 billion. In 2016, Indonesia's e-commerce sales as a percentage of total annual retail sales amounted to 1.6 per cent, compared to 13 per cent in China. These percentages suggest there is still a room for growth in the Indonesian e-commerce market, which is likely to be led by the ongoing transformation through the industry via high levels of investment and industry consolidation (Austrade, 2018). Several current limitations regarding existing infrastructure and other issues related to the economical and sociocultural conditions become a barrier for e-commerce business growth (Lawrence \& Tar, 2010). Other problem also appears such as the lack of awareness on the great potential of e-commerce, which is one important barrier in its adoption (Agwu et al.,

* Corresponding author. Email address: daduk1600@unpad.ac.id 
2015). Even e-commerce has a potential business revenue on huge number in developing country, but the fact is still on low level status (Makame, et al., 2014). Many factors also become barrier for the low usage of e-commerce and until today the condition is still not clear which factors could influence the use of e-commerce (Ndyali, 2013). E-commerce is a very important aspect for economic growth, in developing countries. Unfortunately, the adoption of e-commerce and the related researches are still limited (Okadapau, 2016).

Literature study shows the main factor as the key success factors for growth of business e-commerce are related with acceptance and the use and from this perspective, some existing researches show it depends on the technology adoption process (Indrawati \& Mansur, 2016). Previous research only focused on SME as a unit analysis rather than individual user like research by Looi (2005), Kartiwi (2006), Macgregor \& Kartiwi (2010), Maryeni et. al, (2012), Rahayu \& Day (2015). E-commerce business potentially has a huge revenue in real money that is come from the personal buyer. According from this condition, it is very important to know what factors that influence on personal/consumer user of e-commerce. E-commerce is changing the face of retailing, travelling and reaching more consumers each year. Nowadays Consumer to Consumer $(\mathrm{C} 2 \mathrm{C})$ on e-commerce is most often conducted in an electronic auction environment (Leonard et al., 2013).

This condition gives strong indication for us to use personality user as unit analysis in this research. Our research has a purpose to find out the fit model that has the capability to predict estimation for adoption of e-commerce consumer behaviour. The model is capable to estimate a few factors that influence the personal digital buying behaviour in the use of e-commerce. The previous research use SME as a unit analysis. From practitioner aspect, the fit model gives significant impact to help the operator of e-commerce to improve their performance and eliminate the gap in both theoretical and empirical on e-commerce business in Indonesia.

\section{LITERATURE REVIEW}

Regarding e-commerce adoption is based on theory behaviour which is rooted in the field of social psychology. Acceptance of e-commerce as a buying tool is related with consumer buying behaviour. Understanding customer behaviour in the opinion of Khaniwale (2015) is a study of how an individual makes the decision to allocate the available resources to consume a product. There are four factors that can affect consumer behaviour, which are culture, social, personality and psychology.

Survey result regarding perception of e-commerce user in Indonesia shows that Trust (T) $(56 \%)$ and Habit $(\mathrm{H})(22 \%)$ provide influence on decision making to accept and use e-commerce (DBS Asian Insight, 2013). Trust (T), give a definition as the degree of believe regarding to integrity and skill provider (Bartikowski, 2015) and also Chin. et.al (2009) shows that Trust (T) on the use of internet will give an influence to the use of e-commerce. Habit $(\mathrm{H})$ is a degree of individual behavior to conduct activity routine (Farzin and Dahlan, 2016).

Preliminary survey that is conducted with 214 respondent which are users of ecommerce show that $41 \%$ of them have a lack trust of security and $45 \%$ show that respondent have an online habit. 


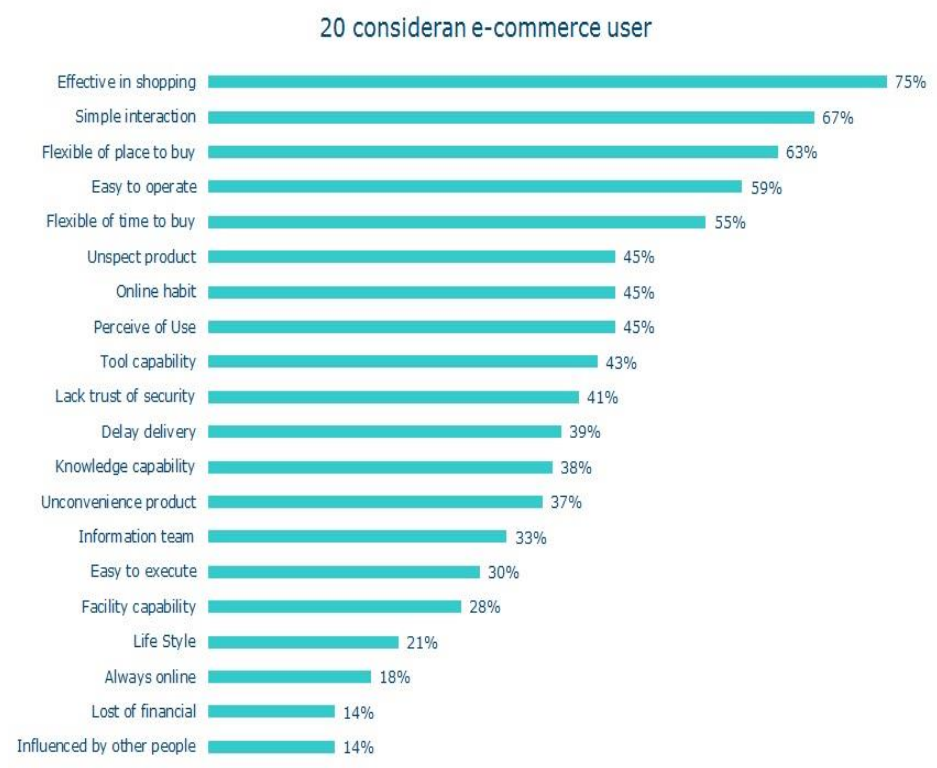

Figure 1 Preliminary Survey Diagram Source: Survey result (2017)

Literature study shows that personal perception i.e. Masa'deh et al., (2016) shows that $\mathrm{H}$ give influence on Behavior Intention (BI), and Jham (2016) shows that $\mathrm{T}$ (Trust) influence on BI and BI influence on Use Behavior (UB).

\section{MODEL AND HYPOTHESIS DEVELOPMENT}

Technology adoption in this research refers to the Unified Theory and Use of Technology (UTAUT) as the strongest theory on technology adoption (Samaradiwakara and Gunawardena, 2014) where the independent variables influence to Behavior Intention (BI) and BI influenced on Use Behavior (UB). We know that ecommerce contains an online transaction, by literature review we found new several variables that meet with the use behavior of e-commerce user in Indonesia. There are some variables that is suitable and are connected with the factors which affects the ecommerce consumption in Indonesia.

Indonesian E-commerce Association already conducts a research. From the survey there are $14.6 \%$ that has problem with transaction process and on the other side $38.4 \%$ have an untrusted issue to buy some product through e-commerce (IDEA, 2016).

According to the literature review above, those several factors that influence to $\mathrm{BI}$ for the use of e-commerce, are:

1. Habit $(\mathrm{H})$ refers to tendency of routine activity (Al Azam et al., 2016), other research by Nair, et. al., (2015) gives definition as a conducted activity automatically.

2. Trust (T) refers to believe regarding competence, integrity and benevolence (Masa'deh et al., 2016). Other research also gives definition as a believer of related reliability, efficiency, security, comfort, dependence and confidence (Jham, 2016).

3. Behavior Intention (BI) refers to the intentional use (Farzin \& Dahlan, 2016). This variable also has definition as an intentional individual that acts to accept and use of a system (Indrawati \& Mansur, 2016).

4. Use Behavior (UB) refers to individual believe usage system (Al Azam et al., 2016). This variable also refers to the frequency of an activity while using the system (Indrawati \& Mansur, 2016).

According the literature review, this research builds a hypothesis which is listed below: 
1. H1: Positive Habit (H) has a significant effect on Behavior Intention (BI) in the use of e-commerce

2. H2: Positive Trust (T) has a significant effect on Behavior Intention (BI) in the use of e-commerce.

3. H3: Positive Behavior Intention (BI) has a significant effect on Use Behavior (UB) in e-commerce.

4. H4: Positive Habit $(\mathrm{H})$ has a significant effect on Use Behavior (UB) in ecommerce.

5. H5: Positive Trust (T) has a significant effect on Use Behavior (UB) in ecommerce.

The model that is used on this research shown in figure 2.

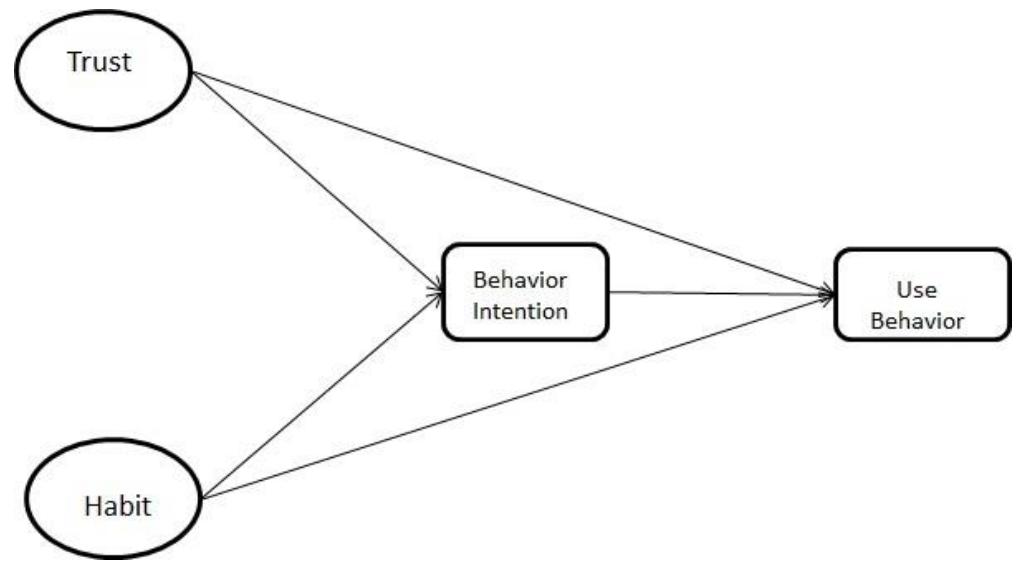

Figure 2 Factors influence to acceptance and use of e-commerce behaviour Source: Research e-commerce behaviour adoption in Indonesia

\section{RESEARCH METHODOLOGY}

This research is developed and validated through the fit model for validation factors that influence to acceptance and the use of e-commerce. By literature review and in-depth interview with the experts as a methodology to develop the model. The model validated and checked by analysis data that gathered from survey. Item that is being surveyed is built by develop construct that refers to previous research which is found from reputation journal.

In this research to build robust questioner, pilot survey had conduct and get 30 respondents with composition of 17 male and 13 female 13 person. Age distributed below 20 years old 10 person, between 20 until 30 years old 10 person and above 30 years old 10 person. After calculated using SPSS 17.0 the result finds 3 items (H1, BI7, UB8) which is the score of Corrected Item-Total Correlation below 0.3 and Cronbach's Alpha if Item Deleted for all items above 0,7. Based on this condition, there is a need to ground a few items for SPSS second processing. After taking process again in SPSS 17.0, the result finds that that the score of Corrected Item-Total Correlation is above 0.3 and Cronbach's Alpha if item is deleted for all items above 0,7. The final result is the proposed model that is ready to be used for validation for the e-commerce consumer behaviour.

Data primer gathered from the survey has a purpose to get primary data with total respondent 547-person $(\mathrm{M}=392, \mathrm{~F}=155)$ with age data $(\mathrm{Age}<20$ yo $=25,20<\mathrm{Age}<30$ yo $=190,30<$ Age $<40$ yo $=208,40<$ Age $<50$ yo $=98$, Age $>50$ yo $=26)$. Data is being analysed using Smart Partial Least Square (PLS) 2.0 for the calculation on statistic parameter. Starting with importing the data survey and continue by building a latent variable and then make direct line for connection between variables in the model. The running result from Smart PLS analysis that influence become significant if T statistic $>1.96$, based on this theory, results of the hypothesis test showed in Table 1 . 
TRUST AND HABIT AS KEY SUCCESS ON DIGITAL CONSUMING BEHAVIOR IN INDONESIA MEDIATED BY BEHAVIOR INTENTION

Table 1 Result of calculation data survey using Smart PLS 2.0

\begin{tabular}{|c|c|c|}
\hline & $\begin{array}{l}\text { T Statistics } \\
(\mid \text { O/STERR } \mid)\end{array}$ & Result \\
\hline Habit -> Behaviour Intention & $7.147381>1,96$ & H1 Received \\
\hline Trust -> Behaviour Intention & $3.768538>1,96$ & H2 Received \\
\hline $\begin{array}{llll}\text { Behaviour Intention } & -> & \text { Use } \\
\text { Behaviour } & & & \end{array}$ & $4.937761>1,96$ & H3 Received \\
\hline Habit -> Use Behaviour & $5.644498>1,96$ & H4 Received \\
\hline Trust -> Use Behaviour & $2.754131>1,96$ & H5 Received \\
\hline
\end{tabular}

Source: Research trust and habit as key success on digital consuming behavior in Indonesia mediated by behavior intention

\section{RESULTS AND DISCUSSIONS}

This research finds factors on personal perception that influenced to e-commerce acceptance and use behaviour. According to that condition, the result of statistical that was calculated found that $\mathrm{H}$ and $\mathrm{T}$ are positively significant to influence on Behavior Intention (BI) and BI is positively significant to influence on Use Behavior (UB). The result also found new important factors compared with some previous research as novelty on consumer behaviour in e-commerce usage for shopping online. Those factors are Trust and Habit which significantly influence directly to e-commerce Use Behaviour.

The findings on this research strengthen and completing the previous research like Macgregor and Kartiwi (2010), that finds perception become barriers to ecommerce adoption in a developed country like Indonesia. Rahayu and Day (2015), find the determinant factors of E-commerce adoption in Indonesia. Those all researches focus on SME as unit analysis. Based on result of research, the model of key success factor is as shown in Figure 3.

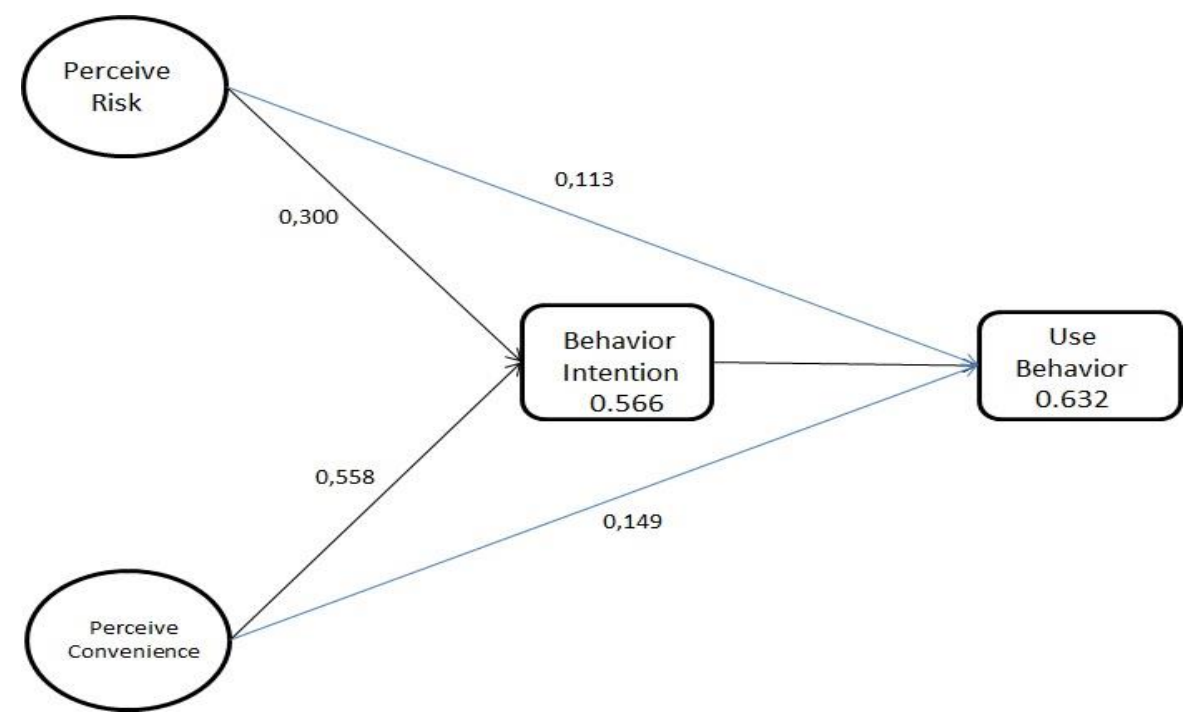

Figure 3 Trust and Habit as the key important factors for acceptance and use E-

Commerce in Indonesia

Source: Research trust and habit as key success on digital consuming behavior in Indonesia mediated by behavior intention

The data for Figure 3 which shows the value of Use Behavior (UB) from Behavior Intention (BI) is shown in APENDIX C (Runing data by Smart PLS Calculate result PLS Algoritm). 


\section{CONCLUSION AND RECOMMENDATION}

This paper has searched and studied a fit model of acceptance and the use ecommerce in Indonesia. We consider that $\mathrm{H}$ (habit) and $\mathrm{T}$ (trust) are supported by a survey, and the statistical data is calculated based on the PLS (Partial Least Square) method. This research can estimate the acceptance and use of e-commerce, so that providers and operators can have tools to conduct evaluations.

Based on the research findings, we found several factors that can influence the user adoption of e-commerce which are Habit $(\mathrm{H})$ and Trust $(\mathrm{T})$. These factors became the main focus of improvement in accordance with the culture and e-commerce user behaviour. The most important academic contribution from this research is finding new variables and proposition that Trust $(\mathrm{T})$ and Habit $(\mathrm{H})$ provide positive influence on the e-commerce use behaviour. Hypothesis test showed that this model fits to prediction and estimation related to the factors that influence to e-commerce use behaviour on online shopping. This model can also help the operators to identify the significant influence variables for the e-commerce services.

From the results of this study, the Use Behaviour (UB) value (shown in Figure 3 ) is equal to 0.632 or $63.2 \%$ which indicates this value is still insubstantial, where only $63.2 \%$ of the factors described are related to Use Behaviour (UB), so there are still several factors that need further researched, for example relating to trust factors and changes in user habits that continue to experience dynamism.

\section{References}

Alekam. (2012). The Influence of Trust, advertising, Family on Intention and Actual Purchase of Local Brand in Yemen. American Journal of Economics, Special Issue: 64-68.

Agwu, e. (2015). Empirical Study of barriers to electronic commerce adoption by small and medium scale business in Nigeria. International Journal of Innovation in the Digital Economy, 1-19.

Alazzam, e. (2016). Pilot Study of EHR Acceptance in Jordan Hospitals by UTAUT 2. Journal of Theoritical and Applied Information Technology, Vol. 85.

AT Kearney. (2015). Lifting The Barriers to E-commerce in ASEAN.

Autrade. (2018). E-commerce in Indonesia: A guide for Australian business was prepared by Amplitude in consultation with the Australian Trade and Investment Commission.

Bartikowski. (2015). Modeling the effects of the three dimensions of trust towards the e-vendor on online consumer behavior. Sistemes d'information et management, Vol. 20, No. 1.

DBS Asean Insigh. (n.d.). E-commerce in Asia: Bracing for Digital Disruption. 2013.

Emarketer. (2015). eMarketer's Updated Estimates for 2015.

Farzin, \& Dahlan. (2016). Proposing a Model to Predict Students Perception toward Adopting an E-Assessment System. Journal of Theoritical and Applied Information Technology.

Gelman. (2013). P Value and Statistical Practice, Epidemiology.

Geven et al. (2000). Trust and TAM in Online Shopping online: an integrated model. MIS Quarterly, 27. 
TRUST AND HABIT AS KEY SUCCESS ON DIGITAL CONSUMING BEHAVIOR

IN INDONESIA MEDIATED BY BEHAVIOR INTENTION

Harsono et al. (2014). Factors Affecting the Use Behavior of Social Media Using UTAUT 2 Model, Proceedings of the First Asia-Pacific Conference on Global Business, Economics, Finance and Social Sciences. AP14Singapore Conference. Singapore.

IDEA. (2016). Study E-commerce Indonesia 2016.

Indrawati, M. (2016). Behavioral Intention to Use @wifi.id in Indonesia. Jakarta: Atlantis Press.

Indrawati. (2014). The Use of Modified Unified Theory of Acceptance and Use of Technology to Predict the Behavioral Intention toward Website. Journal Applied Mechanics and Materials, 568-570.

Indrawati. (2015). Metode Penelitian Manajemen dan Bisnis: Konvergensi Teknologi Komunikasi dan Informasi. Bandung: Refika Aditama.

Indrawati. (2015). The Use of Modified Theory of Acceptance and Use of Technology 2 to Predict Prospective Users: Intention in Adopting TV Streaming.

Jham. (2016). Customer satisfaction whit internet banking: explorating the mediating role of trust. Journal of Emerging Trends in Economics and Management Sciences (JETEMS), 75-87.

Kartiwi. (2006). Case Studies of E-commerce Adoption in Indonesia SME's: The evaluation of strategic use. Australian Journal of Information Systems, 69-80.

Khaniwale. (2015). Consumer Buying Behaviour. International Journal of Innovation and Scientific Research, 278-286.

Kurnia et al. (2015). E-commerce technology adoption: A Malaysian grocery SME retail. Journal of Business Research, 1906-1918.

Lawrence, \& Tar. (2010). Barriers to e-commerce in developing country, Information, Society and Justice. 23-35.

Leonard et al. (2013). Consumer to Consumer e-commerce: Acceptance and Intended Behaviour, Communications of the IIMA.

Looi. (2005). E-commerce adoption in Brunei: A quantitative analysis of factor influencing in adoption. Communications of the Association for Information Systems . 61-81.

Macgregor, \& Kartiwi. (2010). Perception of barriers to e-commerce adoption in SME in a developed and developing country: a comparison between Australia and Indonesia. Journal of Electronic Commerce in Organizations, 61-82.

Makame et al. (2014). Factors influencing electronic e-commerce adoption in developing countries: The case of Tanzania. 45.

Maryeni et al. (2012). Organizational factors influencing the e-commerce adoption by Indonesian SME's. 3rd International Conference on Business and Economic Research (3rd ICBER 2012). 
Masa'deh et al. (2016). Modelling Factors Affecting Student's Usage Behaviour of ELearning Systems in Lebanon. International Journal of Business and Management, Vol. 11.

Nair et al. (2015). Factors Affecting Acceptance \& Use of ReWIND: Validating the Extended Unified Theory of Acceptance and Use of Technology. Emerald insight Interactive Technology and Smart Education.

Ndyali. (2013). Adaptation and Barriers of e-commerce in Tanzania Small and Medium Enterprises, Developing Country Studies. Retrieved from www.iiste.org.

Okadapau. (2016). State and Extend of Electronic Commerce Adoption Among SMEs in Kenya. Journal of Emerging Trends in Computing and Information Sciences.

Rahayu, \& Day. (2015). Determinant factors of E-commerce adoption by smes in developing country: Evidence from Indonesia, Social and Behavioural Sciences. 142-150.

Samaradiwakara, \& Gunawardena. (2014). Comparison of existing technology acceptance theories and model to suggest a well improved theory/model. International Technical Sciences Journal (ITSJ).

Vankatesh, V., Morris, M., \& Davis, G. (2003). User Acceptance of Information Technology: Toward a Unified View. MIS Quarterly, 425-478. Alekam. (2012). The Influence of Trust, advertising, Family on Intention and Actual Purchase of Local Brand in Yemen. American Journal of Economics, Special Issue: 64-68. 